\title{
Cognitive models of future in political texts
}

\author{
Solopova Olga Alexandrovna \\ Department of Linguistics, Chelyabinsk. Russian Federation, South Ural State University (National Research University)
}

Email address:

solopovaolga@yandex.ru

\section{To cite this article:}

Solopova Olga Alexandrovna. Cognitive Models of Future in Political Texts. International Journal of Language and Linguistics. Vol. 2, No. 1, 2014, pp. 1-4. doi: 10.11648/j.ij11.20140201.11

\begin{abstract}
The present paper briefly recalls theoretical preconditions for investigating cognitive-discursive models of future in political discourse. The author reviews theories and methods used for strengthening a future focus in this discourse and works out two main tools - a model of future and a metaphorical scenario. The paper examines the implications of metaphorical analogies for modeling future in mass media. It argues that metaphor is not merely a rhetorical ornament in the political discourse of media regulation but a conceptual model that legislates and regulates our understanding of future. The metaphorical scenario includes several frames, namely, "Actors, "Space and Time", "Reason and Consequence" that answer certain metaphorical questions that determine the image of future.
\end{abstract}

Keywords: Cognitive Approach, Future Research, Political Discourse, Model, Scenario, Metaphor

\section{Introduction}

The future is obviously a feature of our understanding of time. Time is inseparable from the person, it models the person as a social being and the person in his turn models time and consequently there is always a temptation to sense and predict future. Nowadays the problem of future has emerged with the utmost urgency. Faced with the complexities and challenges of the times, much effort has gone into the development of models and scenarios through which to comprehend the future of a country and to guide the navigation of policy-makers.

\section{Prospective Function of Political Discourse}

Core analytical concepts include visions, projections, forecasts and plans [1], and continuities of past, present and future. In the world of forecasts the object of our analysis is political projections, with the political system and political processes being its main targets. The essential distinctions among vision, projection and forecast are proposed by A. Isserman [2]. A projection is not a prediction but merely the result of entering hypothetical assumptions into a mechanistic quantitative procedure. Projections are not predictions of the way the future must or will unfold. They are only mechanical exercises that spell out the future implications of current trends or past ratios without assessing the validity of the assumptions used to make the projection.

A string of recent articles and books has stressed prospective functions of political discourse. That's due to the fact that politicians and journalists often reckon the experience of their predecessors, try to evaluate the present situation and either promise «extrinsic benefits that are contingent on a candidates' victory in the election» [3] or threaten the public with the coming catastrophes.

E. Lassan points out that the triple opposition "past-present-future" is one of the most important valuable oppositions contemporary political discourse based on [4]. Insights into prospective function of political discourse can be drawn from D. Graber who holds that any political discourse includes prediction of the future and reflection on the past [5]. G. Lakoff places the future among five implicit categories that define both a progressive culture and a progressive form of government, and encompass all progressive policies. That is the moral perspective [6].

A. Chudinov stresses structuring function of metaphor. He has come to an understanding that metaphors play a crucial role in framing a world model and comprehending interrelation between its elements [7]. T. Shmeleva thinks "communicative future" to be an integral part of any speech genre [8]. E. Sheygal considers proclamation of political policy for the future among the dominant characteristics of inaugural speech [9]. V. Dauletova exploring the genre of political autobiography also pays special attention to "communicative future" [10].

The advantage of the cognitive approach is the ability to 
determine mental schemas or cognitive models underlying any political text [11]. The structure and content of these cognitive models are important to effectively study the mode of thinking of those who represent political and non-political institutions in a particular historical period. They also allow to build "predictive models in political science" [12].

A growing number of recent linguists have been trying to establish metaphor at a cognitive, conceptual level. One of the fundamental findings of cognitive science is that people think in terms of frames and metaphors. G. Lakoff places the human act of cognition in the center of attention; his brilliantly presented result is that cognition is vitally dependent on metaphor, which he defines as a mapping of conceptual structures from one domain onto another [13]. He says that framing is about getting language that fits your world view. It is not just language. The ideas are primary - the language carries and evokes those ideas [14].

Scholars stress the crucial importance of metaphor in discourse interaction: many accounts of figurative schemas and language are concerned with: (a) what is conceptualized in terms of something else and how this process takes place; (b) exploring metaphors in various genres of political discourse; (c) cognitive rhetoric, etc. Metaphorical thinking is to some extent necessary and unavoidable; it advocates a critical stance with respect to the utilization and circulation of metaphor, shaping the future at the same time.

\section{Objective and Methods}

Investigating cognitive-discursive models of future in political discourse is supposed to be a new synthesis of theories and conceptions of future proposed in future studies, political science and cognitive linguistics. Using tools of future studies and cognitive linguistics, this approach studies models of future which are based on exploratory forecasts made by authors of political texts. Thus, the basic constituents of the methods are models of future and scenarios in the political discourse of different chronological periods. A cognitive-discursive model of future serves a basis for scenario development, a scenario in its turn being its linguistic representation. The central tool in any scenario is a cognitive metaphor. The main objective is to draw attention to the prospective function of metaphor framing it within such a purposeful typified activity as political discourse. This aims at understanding what interpretation of future events we can reconstruct from analyzing the metaphors used in this discourse.

\section{Cognitive-Discursive Models and Scenarios}

Cognitive-discursive future research is concerned with elaborating models and scenarios of future in political discourse of different chronological periods. A cognitive-discursive model is used as a tool to get an idea of possible options for future development of society, helps to better understand the driving forces shaping it. In other words such a model is identification of drivers and trends.

\subsection{Working out a Metamodel}

The metamodel used in the approach is a matrix - "methodology of forecasting and historical models" [15] covering the evolution of various parameters of Russian socio-political system. Many different trends occupy the same historical time line. Examples include population, housing, changing technology, financial markets, and the rise and fall of political regimes. These parallel trends are not independent and are clearly linked. Forecasts often address only a limited set of possible historical trends, focusing on one part of die future to the exclusion of other factors. As the author's interest is political discourse, the process of constructing the metamodel (which in fact is a system of parameters) includes creating a conceptual model of political future. Its basic components are domestic and foreign policies. Basic parameters (domestic policy and foreign policy) in their turn can be divided into subsets - factors most frequently addressed in mass media when referring to the image of Russia's future.

These subsets are quite numerous. In order to reduce the level of complexity they therefore have to be consolidated into some generic categories. So the basic parameter "foreign policy" is divided into the following subsets: relations with the USA, relations with Europe, and relations with CIS ("near abroad"), relations with Asian countries. The basic parameter "domestic policy», in its turn, can be divided into the subsets: politico-economic situation, population, natural resources, and armed forces.

Models are constructed for each historical period analyzed. They are based on the data obtained from a particular discourse - Russian, American or British - of a certain chronological period. These are static matrices used to compare differences and similarities of models in political discourses of Russia, the US and Britain. Dynamic matrices are used to reveal development, deterioration or amelioration of models in the political discourse of one and the same country throughout different chronological periods. They are supposed to be an intelligent understanding of the dynamic processes by which the future evolves and may be shaped. The purpose of the model is to cover the areas and possible trends.

\subsection{Scenario-Writing}

A cognitive-discursive scenario, as it has been stated above, is a sort of linguistic representation and verbalization of each conceptual model. Scenario-writing is especially useful to politicians as a way of sensitizing themselves to the various possibilities of the future, which can then be planned for (or against). Scenarios can be either state or process driven. State scenarios are those that offer a vision of what the world will be like at a specified point in the future without describing the process by which this end state is achieved (in our research these are scenarios constructed for a static model). By contrast, process scenarios describe the 
circumstances and sequence of events through which a particular vision or end state is realized (in our research these are scenarios constructed for any dynamic model). In P. Schwartz's conception, the value of scenario-building lies not in predicting the future but in preparing to respond intelligently to whatever the future holds in store [16].

Thus, cognitive-discursive scenarios describe two alternative futures, one a best-case scenario and the other a worst-case scenario. These scenarios are not meant to be credible but rather to provoke response by contrasting two alternative views of the future. In this sense they are more like visions. They neither act as guides to preparation nor suggest strategies for action, but instead rally interest and prod people into thinking about possibilities of future, scenario axes being its two extremes.

Cognitive-discursive scenarios are developed in exploratory manner. Exploratory scenarios are concerned with the uncertainties of the future [17]: they are created in order to understand how different the future may become and what may drive these changes. Exploratory scenarios are a systemic understanding of how several trends will extend forward and interact with one another, shaping new possibilities and patterns of behavior in the process. These scenarios are purely model-based. Scenarios are tools created to structure analysis of opportunities that future may bring. They highlight challenges and dynamics of each particular model of future and differ from one another in strategically significant ways. Thus, scenarios demystify the future by reducing complexities while bringing several perspectives into consideration at the same time.

\subsection{Scenarios and Metaphor}

The central tool in a cognitive-discursive scenario is a cognitive metaphor. Traditional tools for divination depend much on metaphor to describe auspicious and inauspicious future conditions. Meant for further conceptual analysis of each model, a cognitive-discursive scenario analyses metaphorical means used to create an image of future. It helps to understand which metaphors are used to describe the dynamics and drivers of change. «Future» can often be understood and foreseen with the help of the answers to metaphorical questions «present» poses.

A scenario includes some frames that form its backbone. They are as follows:

-The frame «Actors» answers the questions: "Who are the most important actors (creators, destroyers, allies, adversaries) in the scenario? How might they be expected to act?" For many "the future can only be understood metaphorically as configured around archetypal figures" [18], personal saviors may take political forms; politico-economic progress for many people is only possible through a patron who is the very focus of projections.

-The second frame in the cognitive-discursive scenario is "Time and Space" analysis. It answers the question: "Where is the future of Russia: in its past, present or future?" The future is not a disconnected end-state that exists only in the future, instead, "the future should be viewed as a continuous unfolding in time that is rooted both in the past and present. Both the past and the future are mediated through the present component of the future" [19]. The past component of the future has to do with all those elements that will be inherited from the past into the future and will have to be accounted for in shaping the present that in its turn shapes the future. One more metaphorical question answered within the frame is "What place will Russia occupy on the geopolitical map?" The time frame and spatial scale of a projection are positively associated with one another.

-The third frame aims at "Reason and Consequence" analysis. The future may be understood in terms of metaphors derived from reasons and consequences, values or the governing order. The questions this frame answers are "Why will it happen?" "What will follow these changes?" The future may be understood in terms of why it is brought about or experienced and what follows it. In this vein, the rapid accumulation of problems and the avoidance of considered response can make of the future a situation in which "the chickens come home to roost" ("grim future"). The adequate response may bring to life "bright future".

\section{Conclusion}

In the contemporary world the media have adopted metaphors as a kind of short cut to understanding that world. The approach proposed in this paper is based on using models and scenarios that help to foresee "different ends" Russia is destined to as viewed by mass media in Russian, American and British political discourses. The present research analyses the selection of metaphors used over an extended period of time to structure perceptions of future in political discourse of a particular historical period. Each model can be realized through at least two scenarios which represent its extremes - "bright" and "grim". The future is understood through the questions it poses.

As a final remark, it must be noted that depicting future either in the most favorable light or portraying it in dark colors is frequent and efficient means used by mass media and politicians in political discourse. The reason for it is one of the main driving forces of all human actions - their hope that one day things will change for the better. On the other hand, "attention should be given to the ways in which metaphors can be used as weapons to entrap and isolate - and even kill" [6] the whole country.

There is a need of negotiation between the role of model and metaphor. Models need the inspiration of rich metaphors. Use of metaphors needs the discipline of modeling. The means for regulation and solving this problem is an exploratory scenario, intermediary between a model and a metaphor.

\section{References}

[1] Bestuzhev-Lada, Igor (2007). Little Russian encyclopedia of future studies. Moscow: Institute of Economic Strategies. 
[2] Isserman, Andrew (1984). Projection, forecast, and plan: on the future of population forecasting, Journal of the American Planning Association, 50 (3), 208-221.

[3] Anderson, Richard. Encouraging democratic participation in Russia: pragmatic ambiguity and identification with political speakers. Retrieved August 13, 2004 from www.sscnet.ucla.edu/polisci/laculty/anderson/modcautx.litm

[4] Lassan, Eleonora (1995). Discourse of power in the USSR: cognitive-discursive analysis. Vilnus.

[5] Graber, Doris (1981). Political languages, handbook of political communication. London.

[6] Lakoff, George (1987). Women, fire, and dangerous things: what categories reveal about the mind. Chicago; London.

[7] Chudinov, Anatoly (2003). Metaphorical mosaics in modern political communication, Ekaterinburg.

[8] Shmeleva, Tatiana (1997). Model of speech genre. Speech Genres, 1(1), 91-92.

[9] Sheigal, Elena (2000). Semiotics of political discourse. Institute of Linguistics of Russian Academy of Science, Volgograd: Peremena.

[10] Dauletova, Victoria (2004).Verbal means of creating an image in political discourse. Krasnodar.
[11] Budaev, Edward, Chudinov, Anatoly (2008). Foreign political metaphorology. Ekaterinburg.

[12] Basilev, Vladimir (2007). Methods of studying the language of Russian political thought in Russian political discourse (traditions and innovations). Political Discourse in Russia, 10(1). 5-10.

[13] Lakoff, George (2004). Don't think of an elephant! Know your values and frame the debate. New York.

[14] Lakoff, George. Framing the dems. How conservatives control political debate and how progressives can take it back. Retrieved December 23, 2002 from http://nww.prospect.org/web/page.ww7section=root\&name= ViewPrint\&articleld=6862.

[15] Mathius, Robin (2003). New matrix or logics of strategic domination. Moscow.

[16] Schwartz, Peter (1996). The art of the long view: planning for the future in an uncertain world. New York, Doubleday.

[17] Akhremenko, Andrew (2004). Political prognostics: methods of scenarios. Moscow: MAKS Press.

[18] Slaughter, Richard (1990). The foresight principle, Futures (October).

[19] Perloff, Harvey (1980). Planning the post-industrial city. Chicago, Ill: APA Planners Press. 